\title{
The Role of Private Environmental Governance in Climate Adaptation
}

\author{
Michael P. Vandenbergh* and Bruce M. Johnson* \\ Vanderbilt University Law School, Nashville, TN, United States
}

This Article examines the role of private environmental governance (PEG) in climate change adaptation. PEG occurs when private organizations perform traditionally governmental functions such as providing public goods and reducing negative externalities. PEG initiatives that target climate change mitigation have expanded rapidly in the last decade and have been the subject of research in multiple fields, but PEG initiatives that target climate change adaptation have received less attention. As a first step, the Article develops a definition of private governance regarding climate adaption, identifies several types of PEG adaptation initiatives, and briefly identifies research gaps.

Keywords: climate change, private environmental governance, climate change adaptation, climate change mitigation, environmental social governance (ESG)

\section{OPEN ACCESS}

Edited by:

Robin Kundis Craig,

The University of Utah, United States

Reviewed by:

Pedro Roberto Jacobi,

University of São Paulo, Brazil

Giuseppe Forino,

University of East Anglia,

United Kingdom

*Correspondence:

Michael P. Vandenbergh

michael.vandenbergh@vanderbilt.edu

Bruce M. Johnson

bruce.johnson@vanderbilt.edu

Specialty section:

This article was submitted to

Climate Risk Management,

a section of the journal

Frontiers in Climate

Received: 26 May 2021

Accepted: 17 August 2021

Published: 10 September 2021

Citation:

Vandenbergh MP and Johnson BM

(2021) The Role of Private

Environmental Governance in Climate

Adaptation. Front. Clim. 3:715368.

doi: 10.3389/fclim.2021.715368

\section{INTRODUCTION}

The private sector is increasingly undertaking private environmental governance (PEG) actions for climate change mitigation, whether through renewable power commitments, supply chain contracting requirements, investor collaborative efforts with non-governmental organizations (NGOs) to pressure companies to set carbon targets or reduce carbon emissions, or other steps. These actions are an important gap-filling effort given the limits of international, national and sub-national climate mitigation, and they can help increase climate mitigation support by moderates and conservatives in the United States who are critical to federal climate legislation (Vandenbergh and Gilligan, 2017; Gillis et al., 2021). But is the same true for adaptation? Are corporations and other private sector actors engaging in meaningful amounts of climate adaptation? If so, when should these activities be considered a form of private governance? How should these PEG adaptation activities be assessed? Should they be celebrated or discouraged?

PEG adaptation is just beginning to be a focus of academic and policy studies. Numerous studies have focused on how governmental bodies in the US and across the globe are engaging in adaptation, but these studies rarely discuss the role of the private sector (Flatt and Huang, 2012; Vogel et al., 2016). For example, the NASA website describes cities and municipalities as being on the frontline of adaptation efforts, but it makes no mention of corporations or other private sector actors (NASA, 2021). Similarly, the most recent IPCC Climate change report on "Impacts, Adaptation, and Vulnerability" also mentions only government adaptation efforts (Intergovernmental Panel on Climate Change [IPCC], 2014). Government and private reports have begun to focus on the private sector's role in adaptation, however, and have identified a substantial and growing amount of PEG adaptation activity (Caring for Climate, 2015).

This article examines the state of PEG initiatives directed at climate change adaptation. Private sector adaptation activities constitute a form of governance in some cases but often do not, and in Part II the article begins by developing a definition of PEG adaptation. Part III then identifies a variety of different PEG adaptation initiatives across multiple sectors, including retail, banking, insurance, and finance. Finally, Part IV concludes that PEG adaptation initiatives are an important 
and growing aspect of the response to climate change, but that substantial research gaps will need to be filled to enable these initiatives to achieve their potential.

\section{DEFINITION}

PEG occurs when non-governmental entities, such as corporations, non-profit organizations, private universities, and religious organizations, perform the traditionally governmental functions of reducing negative externalities, providing public goods, managing common pool resources, or providing a more equitable distribution of goods and services (Vandenbergh, 2013). In the last two decades, a growing literature has examined private climate mitigation initiatives (Hall and Bierstecker, 2002; Bernstein and Cashore, 2007; Abbot and Snidal, 2009; Light and Orts, 2015; Vandenbergh and Gilligan, 2015; Kousky and Light, 2019). No systematic analysis in the legal literature has examined private governance regarding climate change adaptation, though, and this article provides an initial roadmap for that effort.

Assessing which types of initiatives constitute PEG adaptation requires distinguishing private from public, mitigation from adaptation, and governance from other actions. We include initiatives within the term "private" if they are not conducted by governments and not conducted principally in response to government laws, policies or programs. We distinguish private actions from public actions not because of any preference for private actions or any naivete about the difficult distinctions on the boundary between private and public, but because private actions are often subject to different motivations and limitations from government actions. For instance, Dicks Sporting Goods bans sales of assault weapons, but many states do not, suggesting that in some cases it may be easier for a private company to engage in gun control than a state or the federal government (Vandenbergh, 2005) ${ }^{1}$.

Focusing on private rather than public governance thus is important because a strength of bottom-up private sector initiatives is that they can bypass polarization to fill gaps in government climate laws, policies, and programs, and complement government action when it occurs (Vandenbergh, 2013). At the same time, a weakness of private sector initiatives is that they are subject to market and social pressures rather than direct electoral pressures, so they can lead to undesirable outcomes when market or social pressures do not align with the public interest. In addition, in the absence

\footnotetext{
${ }^{1}$ An important definitional question is when an activity is simply a response by a regulated entity to government through regulation or financial incentives as opposed to a response to drivers arising from NGOs and other private sector actors. It may be possible to conduct PEG adaptation activities even when governments are captured through gerrymandering, ideology, and other limits on the responsiveness of politicians to public preferences and to pursuing public welfare. See Vandenbergh and Gilligan (2015). In short, PEG adaption efforts may be able to bypass some of the political hurdles to government action, such as world views and resistance to climate change acceptance. Eriksen et al., Reframing adaptation: The political nature of climate change adaptation, https:// www.sciencedirect.com/science/article/pii/S0959378015300509. PEG actors are not beholden to the restraints of representative government, but whether the social license and market pressures they face yield actions that are more representative of public preferences is beyond the scope of this article.
}

of a top-down, systematic analysis, the scope of the private governance opportunity may be overlooked by public and private policymakers and inefficient allocation of resources may occur (Vandenbergh, 2013).

We focus in this article on adaptation rather than mitigation, although we acknowledge that some actions can have elements of both. For our purposes, climate change mitigation involves reducing the causes of climate change through decreasing the release of GHG emissions into the atmosphere or increasing GHG sinks (Intergovernmental Panel on Climate Change [IPCC], 2014; Fawzy et al., 2020). Examples of PEG climate mitigation initiatives include supply chain contract provisions that require lower carbon goods and collaborative efforts to induce companies to use renewable energy, such as Walmart's Project Gigaton. Louis Leonard has argued that PEG climate mitigation initiatives constitute a loosely-coordinated private regulatory system (Leonard, 2020).

In contrast to mitigation, adaptation involves actions that reduce the harms that arise from climate change (Intergovernmental Panel on Climate Change [IPCC], 2014) ${ }^{2}$. The IPCC has defined climate adaptation as "the process of adjustment to the actual or expected climate and its effects," and has noted that adaptation actions seek to moderate harm or exploit beneficial opportunities, as opposed to reducing the amount of climate change (Intergovernmental Panel on Climate Change [IPCC], 2014). Adaptation includes both imminent actions such as responses to impending climate disasters and non-imminent actions such as accounting for increased sea level when renovating or constructing infrastructure (Moser and Ekstrom, 2010). Adaptation also includes anticipatory measures taken in advance to minimize the expected negative impact of climate change, as well as reactive measures taken after negative impacts occur. Adaptation efforts may address a wide range of outcomes, including water resources, coastal resources, air quality, agriculture, and public health (Smith and Lenhart, 1996).

The principal challenge for defining PEG adaptation is to identify when private sector adaptation initiatives constitute a form of governance. Governance is not the same as government and can include the processes, mechanisms and organizations through which actors influence environmental actions and outcomes (Lemos and Agrawal, 2006; Biermann et al., 2010). If governance only refers to how society collectively sets goals and makes decisions on how to achieve them (Chaffin et al., 2016), then much of the private sector activity on adaptation is not governance. If governance also refers to situations in which the private sector performs traditionally governmental functions, however, then many adaptation actions do fall within the private governance definition.

To be considered a form of governance under our definition, an adaptation action must perform a function typically assigned to governments such as reducing negative externalities, providing

\footnotetext{
${ }^{2}$ Due to the inertia in the climate system and in public climate governance, substantial amounts of adaptation will be necessary even if prompt, major mitigation efforts are undertaken in the near term. IPCC, Climate Change 2007: Mitigation of Climate Change 818 (B. Metz et al., eds., Cambridge University Press 2007).
} 
public goods, managing common pool resources, and providing a more equitable distribution of goods and services (Vandenbergh, 2013, Light and Vandenbergh, 2016). Thus, to be within the PEG adaptation definition, an adaptation initiative should provide the type of societal benefits typically provided by government laws, policies and programs. In addition, to constitute private governance the initiative should not simply be the result of a government regulatory measure.

An example highlights the importance of our functional definition. If a company, under pressure from NGOs, employees and neighbors, includes a town within its new sea wall, it is providing a public good to the town and engaging in PEG adaptation. In contrast, many private adaptation efforts that do not qualify exclusively benefit the business, rather than providing a benefit beyond the business. If the company builds a sea wall around its plant but excludes neighboring properties, it is adapting to climate change, but it is simply protecting its assets and is not engaging in governance. Of course, on the margin these activities are difficult to distinguish-even simply making a profit serves the social goal of increasing overall prosperity, for example. But our research suggests that despite the line-drawing difficulties, many activities fall easily into the governance category, and understanding the drivers and effects of these activities can contribute important insights about ways to facilitate climate change adaptation in an era of insufficient government action on climate change.

Finally, the legal and political science literatures often refer to governance as the exercise of authority. In this view governance occurs when one party exercises control over another or when multiple parties agree to exercise control over one another (Green, 2013; Salzman and Thomson, 2019). Although we recognize that this is an intuitive and common formulation, we do not include it in our definition. To the extent authority equates to coercion in this view, a large number of activities that government engages in do not involve the use of coercion, yet these actions are not typically excluded from the definition of governance. Examples include some uses of subsidies (e.g., many oil and gas and agricultural subsidies) and the disclosure of information that enables more informed decision making [e.g., the National Environmental Policy Act environmental disclosures [National Environmental Policy Act (NEPA), 1969] and the Toxic Release Inventory toxics disclosures (Emergency Planning Community Right-To-Know Act [EPCRA], 1986)]. As a result, although we acknowledge that private governance in some cases involves the exercise of authority by one party over another, we do not view this exercise of authority as a requirement of PEG adaptation.

\section{EXAMPLES}

Although much of the policy literature on adaptation focuses on public governance, the United Nations Framework Convention on Climate Change (UNFCCC) maintains a database of private sector adaptation initiatives. In addition, recent reports by UNEP and other organizations discuss adaptation efforts by the private sector [Caring for Climate, 2015; United Nations Framework Convention on Climate Change (UNFCCC), 2021]. In Part III we discuss several examples of initiatives that meet our definition of PEG adaptation. These are not a representative sample and we have not assessed their merits, but they demonstrate the range of PEG adaptation activities underway around the world. The net effect of the adaptation activities remains to be addressed, and our selection of these examples does not represent a judgment that they are successfully achieving adaptation or are having a net positive effect. In addition, our discussion of these examples focuses on whether a private sector actor is performing an adaptation function, rather than the actor's motivation for doing so.

\section{Retail}

Coca Cola has collaborated with the World Wildlife Fund and other organizations to establish watershed restoration and community natural resource management projects in Vietnam and Thailand (UNFCCC, 2012a). Coca-Cola set the goal to return to communities an amount of water equivalent to what it uses in the production of all its products, in part through replenishing water via local restoration projects. These local adaptation initiatives have public and private benefits. They increase long term production stability by protecting and replenishing water supplies, which in turn protects the surrounding communities (who often make up the workforce) and the resources needed to make products. Coca-Cola initially selected specific watersheds based on their biodiversity and potential for conservation gains. The effort also supports local communities through water quality testing, wastewater treatment, and financing. Coke has continued to engage in similar watershed improvement projects throughout the world [World Wildlife Fund, 2015; United States Department of Agriculture (USDA), 2016], but critics have question whether these types of efforts are a sustainable model for Coke and other corporations to follow or are just greenwashing (Ward, 2014).

Mars has engaged in PEG adaptation efforts in a variety of ways, including its efforts with Basmati rice farmers in Pakistan (Caring for Climate, 2015). Recognizing that climate change effects in the region coupled with widespread farming deficiencies threaten the supply of Basmati rice, Mars worked with Rice Partners Ltd. to develop a program to decrease water usage and improve rice farming practices. The program aimed to educate roughly 500 farmers about alternative practices that use less water and require fewer inputs, and then encouraged the farmers to share lessons learned with others to drive wider adoption of efficient practices. To determine practices to promote, Mars conducted assessments of current farming practices and invested in research on less waterintensive alternatives. Mars has set both engagement rate and water reduction percentage goals, and projects these alternative practices could increase net income for farmers by $30 \%$.

\section{Insurance}

The insurance industry is well-positioned and motivated to engage in climate change adaptation. For example, reinsurance companies Swiss Re (UNFCCC, 2012c) and Munch Re (UNFCCC, 2012b) have supported adaptation in 
developing countries via innovative insurance-related risk management tools.

In collaboration with the Ethiopian government, Oxfam, and other partners, Swiss Re developed the Horn of Africa Risk Transfer for Adaptation (HARITA) project to assist poor farmers, combining financing of community climate resilience projects with weather risk insurance and microcredit (UNFCCC, 2012c). The program allows cash-poor farmers to work for their insurance premiums through community-identified projects that improve irrigation and soil management, thus reducing risk and building climate resilience. The success of this project is measured by the number of people it serves and whether poorer farmers can "graduate" financially to pay in cash. This project serves as an example of public-private collaboration and stakeholder involvement, and it highlights the potential for positive spillover effects.

In the United States, the insurance industry is engaging in PEG adaptation in response to the increasing risks of sea level rise and flooding. Private insurers are increasingly wary of insuring properties that are subject to flooding and are increasing rates or denying coverage in these areas (Light, 2021). These private actors are thus pushing their insureds to adapt to climate change even though governments are often undermining market incentives, such as by subsidizing flood insurance (Klein, 2021).

\section{Banking}

Many banks are also becoming involved in PEG adaptation efforts. For instance, large mortgage lenders may account for the risks of sea level rise and increasing storm damage over a thirty-year period, and they are beginning to account for these types of climate risks, such as by requiring larger down-payments (Keenan and Bradt, 2020; Klein, 2021). These mortgage lenders are thus engaging in adaptation even as the federal government continues to both directly and indirectly encourage development in coastal areas subject to sea level rise Disincentivizing building in risky areas is a form of anticipatory climate adaptation, but whether the mortgage lenders' actions qualify as a form of governance depends on the extent to which these measures benefit the community, not just the lender.

Banks engage in some activities that more clearly qualify as PEG adaptation. For example, Banco do Brasil conducted assessments across various watersheds in Brazil to assess climate change vulnerabilities (Caring for Climate, 2015). It determined that conventional agriculture processes (such as inadequate soil management), coupled with a lack of local knowledge regarding sustainable alternatives, put many watersheds at particular risk. In response, Banco do Brasil developed the Aqua Brasil program, which it funded and developed in partnership with Brazil's National Water Agency and WWF-Brasil. The program coordinates and funds actions that foster the development and the dissemination of sustainable rural production practices to improve water levels and the quality of target watersheds. Farmers also can receive financial incentives (funded by the bank) to adopt sustainable technology. The program has helped produce $60 \%$ reduction of erosion in some watersheds.

\section{Finance}

The private sector is helping fill the need for financing climate adaptation, and the United Nations Development Project (UNDP) has prioritized increasing private sector funding of adaptation efforts (Olhoff and Bee, 2016). For instance, the market for corporate green bonds, which are bonds whose proceeds are committed specifically to finance climate-friendly projects, has grown substantially since the early 2010s. In 2018, the corporate sector, including large companies like Toyota, Apple, and Unilever, issued green bonds worth \$95.7B (Flammer, 2020). Although green bonds mostly focus on mitigation, many green bonds serve a distinct governance function regarding climate adaptation. Unilever, for example, has set climate adaptation requirements for its green bonds (Unilever, 2019). Because the green bond market is not publicly regulated, private voluntary certification systems, such as Climate Bond Standards and the Climate Resilience Principles have been developed to increase transparency and mitigate concerns of greenwashing (Climate Bonds Initiative, 2018).

\section{Energy}

Energy Development Corporation (EDC) Philippines, has engaged in PEG adaptation efforts in response to recent typhoons (Tall et al., 2021). In addition to increasing the resilience of existing infrastructure with the support of a peso-denominated green bond issued by the International Finance Corporation, EDC is boosting community resilience through training on disaster response for schools, residents and local government officials. It has also established a network of first responders at project sites across the country.

\section{CONCLUSION}

We view PEG adaptation as a discrete, conceptually coherent phenomenon that is an increasingly important feature of the social response to climate change. The barriers to government climate adaptation efforts suggest that public sector adaptation efforts will be inadequate, and although some private sector climate adaptation efforts are simply risk management efforts that benefit only the company, a growing number of activities qualify as PEG adaptation. These PEG adaptation efforts range from sea wall construction to green bonds to programs targeting more efficient water management by farmers.

Research is just beginning into PEG adaptation, however, and it will be important to develop design principles that increase the likelihood that future PEG adaptation activities will fare well when evaluated based on efficacy, transparency, accountability, equity, spillover effects and other criteria. Research is also needed on the drivers of PEG adaptation. A 2012 study by Caring for Climate of 72 companies found that $86 \%$ believe that investing in adaptation creates business opportunities (Caring for Climate, 2012). Additional drivers of PEG adaptation are likely to include not only new business opportunities and risk avoidance, but also reputational concerns, retail and corporate customer pressure, investor, lender and insurer pressure, employee pressure, and manager norms (Vandenbergh and Gilligan, 2017). 
Research is also needed on the extent to which PEG adaptation brings additional private sector funding to government adaptation efforts or undermines government funding, whether greater efficiencies are achieved with PEG adaptation, and whether PEG adaptation decreases or increases support for other adaptation efforts and for mitigation efforts. Initial work on adaptation and geoengineering, however, suggests a general theme: if a response is proposed as a supplement to mitigation, not as a solution, then negative spillover effects on policy support for mitigation are low (Truelove et al., 2014; Raimi et al., 2019), but much more work remains to be done on these issues.

Simply put, PEG adaptation is underway, and far too little is known about its potential drivers, challenges, benefits, and risks. The sooner these research gaps are filled, the sooner public

\section{REFERENCES}

Abbot, K., and Snidal, D. (2009). "The Governance triangle: regulatory standards, institutions, and the shadow of the state," in The Politics of Global Regulation, eds W. Mattli, and N. Woods (Princeton, NJ: Princeton University), 44-88. doi: $10.1515 / 9781400830732.44$

Bernstein, S., and Cashore, B. (2007). Can non-state global governance be legitimate?: an analytical framework. Regul. Governance 1, 347-371. doi: 10.1111/j.1748-5991.2007.00021.x

Biermann, F., Betsill, M., Gupta, J., Kanie, N., Lebel, L., et al. (2010). Earth system governance: a research framework. Int. Environ. Agreements10, 277-298. doi: 10.1007/s10784-010-9137-3

Caring for Climate (2012). Adapting for a Green Economy: Companies, Communities and Climate Change. A Caring for Climate Report. UN Global Compact. Available online at: http://pdf.wri.org/adapting_for_a_green_ economy.pdf (accessed May 25, 2021).

Caring for Climate (2015). The Business Case for Responsible Corporate Adaptation: Strengthening Private Sector and Community Resilience. A Caring for Climate Report. UN Global Compact Office. Available online at: https://d306pr3pise04h. cloudfront.net/docs/issues_doc\%2FEnvironment\%2Fclimate\%2FAdaptation2015.pdf (accessed May 25, 2021).

Chaffin, B., Garmestani, A., Gunderson, L., Benson, H. M., Angeler, D., Arnold, C. G., et al. (2016). Transformative Environmental governance. Annu. Rev. Environ. Resour.41, 399-423. doi: 10.1146/annurev-environ-110615-0 85817

Climate Bonds Initiative (2018). Climate Resilience Principles. Available online at: https://www.climatebonds.net/climate-resilience-principles (accessed September, 2019).

Emergency Planning and Community Right-To-Know Act [EPCRA]. (1986). 42 U.S.C. 116

Fawzy, S., Osman, A., Doran, J., and Rooney, D. (2020). Strategies for mitigation of climate change: a review. Environ. Chem. Lett.18, 2069-2094. doi: 10.1007/s10311-020-01059-w

Flammer, C. (2020). Corporate Green Bonds Benefit Both Companies and the Environment. The Fin Reg Blog Duke Law School. Available online at: https:// sites.law.duke.edu/thefinregblog/2020/07/21/corporate-green-bonds-benefitboth-companies-and-the-environment/ (accessed July 21, 2020).

Flatt, V., and Huang, L. (2012). Climate Change Adaptation: The Impact of Law in the Private Sector. Center for Progressive Reform Briefing Paper. Available online at: https://ssrn.com/abstract=2120083 (accessed August 1, 2012).

Gillis, A., Vandenbergh, M., Raimi, K., Maki, A., and Wallston, K. (2021). Convincing conservatives: private sector action can bolster support for climate change mitigation in the United States. Energy Res. Soc. Sci.73:101947. doi: 10.1016/j.erss.2021.1 01947

Green, F. (2013). Rethinking Private Authority: Agents and Entrepreneurs in Global Environmental Governance. Princeton, NJ: Princeton and private policymakers will have the information necessary to know which types of PEG adaptation to pursue and which to discourage.

\section{DATA AVAILABILITY STATEMENT}

The original contributions presented in the study are included in the article, further inquiries can be directed to the corresponding authors.

\section{AUTHOR CONTRIBUTIONS}

Both authors listed have made a substantial, direct and intellectual contribution to the work, and approved it for publication.
University Press. doi: 10.23943/princeton/9780691157580.00 1.0001

Hall, R. B., and Bierstecker, T. (2002). The emergence of private authority in global governance. Cambridge: Cambridge University Press. doi: 10.1017/CBO9780511491238

Intergovernmental Panel on Climate Change [IPCC]. (2014). Climate Change 2014 Impacts, Adaptation, and Vulnerabilities. Available online at: https://www. ipcc.ch/site/assets/uploads/2018/03/ar5_wgII_spm_en-1.pdf (accessed August 2, 2021).

Keenan, J., and Bradt, J. (2020). Underwaterwriting: from theory to empiricism in the regional mortgage markets in the U.S. Climate Change 162, 2043-2067. doi: 10.1007/s10584-020-02734-1

Klein, P. (2021). Underwater Mortgages for Underwater Homes: The Elimination of Signals in the Coastal Lending Market. Vanderbilt L. Rev. 74.

Kousky, C., and Light, S. (2019). Insuring Nature. Duke L. J. 69, 323-376.

Lemos, M. C., and Agrawal, A. (2006). Environmental governance. Annu. Rev. Environ. Res. 31, 297-325 doi: 10.1146/annurev.energy.31.042605.135621

Leonard, L. (2020). Under the Radar: A Coherent System of Climate Governance, Driven by Business. Environmental Law Reporter. Available online at: https:// papers.ssrn.com/sol3/papers.cfm?abstract_id=3598219 (accessed July 2, 2020).

Light, S. (2021). Banks and climate governance. Columbia L. Rev. 122.

Light, S., and Orts, E. (2015). Parallels in Public and Private Environmental governance. Mich. J. Environ. Admin. L. 5, 2-71.

Light, S., and Vandenbergh, M. (2016). "Private environmental governance," in Environmental Decision Making, Encyclopedia of Environmental Law, eds R. Glicksman, and L. R. Paddock (Edward Elgar). doi: 10.4337/9781783478408.II.19

Moser, S., and Ekstrom, J. (2010). A framework to diagnose barrier to climate change adaptation. PNAS 107, 22026-22031. doi: 10.1073/pnas.1007887107

NASA (2021). Responding to Climate Change: Mitigation and Adaptation. Available at https://climate.nasa.gov/solutions/adaptation-mitigation/ (accessed April 19, 2021).

National Environmental Policy Act (NEPA). (1969). 42 U.S.C. $\$ 4321$ et seq.

Olhoff, A., and Bee, S. (2016). The Adaptation Finance Gap Report. United Nations Environmental Program. Availible online at: https://www.researchgate. net/publication/307476564_The_Adaptation_Finance_Gap_Report_2016 (accessed May 25, 2021).

Raimi, K., Maki, A., Dana, D., and Vandenbergh, M. (2019). Framing of geoengineering affects support for climate change mitigation. Environ Commun. 13, 300-319. doi: 10.1080/17524032.2019.1575258

Salzman, J., and Thomson, B. (2019). Environmental Law and Policy. St. Paul, MN: Foundation Press.

Smith, J., and Lenhart, S. (1996). Climate change adaptation policy options. Climate Res. 6, 193-201. doi: 10.3354/cr006193

Tall, A., Lynagh, S., Blanco, V., Bardouille, P., Montoya, P., Shabahat, E., et al. (2021). Enabling Private Investment in Climate Adaptation and Resilience: Current Status, Barriers to Investment and Blueprint for Action. 
Washington, DC: World Bank Report. Available online at: https:// openknowledge.worldbank.org/handle/10986/35203 (accessed April $16,2021)$.

Truelove, H. B., Carrico, A., Weber, E., Raimi, K., and Vandenbergh, M. (2014). Positive and begative spillover of pro-environmental behavior: An integrative review and theoretical framework. Global Environ. Change 29, 127-138. doi: 10.1016/j.gloenvcha.2014.09.004

UNFCCC (2012a). Building Reputations, Securing Resources: Teaming Up for Water Conservation. Available online at: https://unfccc.int/files/ adaptation/application/pdf/the_coca_cola_company.pdf (accessed August $8,2021)$.

UNFCCC (2012b). Building Alliances Around Climate Insurance. Available online at: https://unfccc.int/files/adaptation/application/pdf/munich_re.pdf (accessed May 25, 2021).

UNFCCC (2012c). Horn of Africa Risk Transfer for Adaptation. Available online at: https://unfccc.int/files/adaptation/application/pdf/swiss_re.pdf (accessed May 23, 2021).

Unilever (2019). Unilever Issues First Ever Green Sustainability Bond. Available online at: https://www.unilever.com/news/press-releases/2014/14-03-19Unilever-issues-first-ever-green-sustainability-bond.html (accessed March 19, 2014).

United Nations Framework Convention on Climate Change (UNFCCC). (2021). Private Sector Initiative (PSI) Database. Avialable online at: https://unfccc.int/ topics/resilience/resources/psi-database (accessed August 8, 2021).

United States Department of Agriculture (USDA). (2016). U.S. Forest Service and Coca-Cola Announce the Restoration of One Billion Liters of Water. Availible online at: https://www.usda.gov/media/press-releases/2016/09/13/ us-forest-service-and-coca-cola-announce-restoration-one-billion (accessed September 13, 2016).

Vandenbergh, M. (2005). The private life of public law. Columbia L. Rev. $105,2029-2096$.

Vandenbergh, M. (2013). Private environmental governance. Cornell L. Rev. 99:129.

Vandenbergh, M., and Gilligan, J. (2015). Beyond dridlock. Columbia J. Environ. L. 40:217. doi: 10.2139/ssrn.25 33643
Vandenbergh, M., and Gilligan, J. (2017). The Private Governance Response to Climate Change. Cambridge: Cambridge University Press. Available at: https://www.cambridge.org/core/books/beyond-politics/ 5B7D5AB62C63D54EC35CBB95D72A47D9 (accessed April 16, 2021).

Vogel, J., Carney, K., Smith, J., Herrick, C., Stults, M., O'Grady, M., et al. (2016). Climate Adaptation: The State of Practice in U.S. Communities. Abt Associates and The Kresge Foundation. Available online at: https://kresge. $\mathrm{org} / \mathrm{sites} /$ default/files/library/climate-adaptation-the-state-of-practice-in-uscommunities-full-report.pdf (accessed May 25, 2021).

Ward, J. (2014). Coca-Cola's New Formula for Water Stewardship: A Government Partnership. Guardian Sustainable Business. Availible online at: https://www. theguardian.com/sustainable-business/coca-cola- usda-water-partnershipwatersheds (accessed February 5, 2014).

World Wildlife Fund (2015). A Transformative Paternship to Conserve Water. Annual Report 2015. Availible online at: https://c402277.ssl.cfl.rackcdn. com/publications/933/files/original/2015_WWF-TCCC_Report-Final.pdf? 1472137155 (accessed August 8, 2021).

Conflict of Interest: The authors declare that the research was conducted in the absence of any commercial or financial relationships that could be construed as a potential conflict of interest.

Publisher's Note: All claims expressed in this article are solely those of the authors and do not necessarily represent those of their affiliated organizations, or those of the publisher, the editors and the reviewers. Any product that may be evaluated in this article, or claim that may be made by its manufacturer, is not guaranteed or endorsed by the publisher.

Copyright (c) 2021 Vandenbergh and Johnson. This is an open-access article distributed under the terms of the Creative Commons Attribution License (CC BY). The use, distribution or reproduction in other forums is permitted, provided the original author(s) and the copyright owner(s) are credited and that the original publication in this journal is cited, in accordance with accepted academic practice. No use, distribution or reproduction is permitted which does not comply with these terms. 